\title{
First report of brown spot disease in Psidium guajava caused by Alternaria tenuissima in China
}

\author{
X. B. Song ${ }^{1}$ - Y. P. Cui ${ }^{1}$ - A. T. Peng ${ }^{1} \cdot$ J. F. Ling ${ }^{1} \cdot$ X. Chen \\ Received: 21 March 2020 / Accepted: 10 June 2020 / Published online: 16 June 2020 \\ (C) Società Italiana di Patologia Vegetale (S.I.Pa.V.) 2020
}

Keywords Alternaria tenuissima $\cdot$ Psidium guajava $\cdot$ Brown spot disease

A new brown spot disease characterized by discontinuous brown or black lesions on branches, wilt and necrosis extending from the edge to the centre of leaves and irregular reddishbrown spots surrounded by yellow halos was recorded on $75 \%$ of guava trees (Psidium guajava L.) on a guava farm of 2 ha in the Nansha District of Guangzhou (113 36 $18^{\prime \prime} \mathrm{E}$ $22^{\circ} 37^{\prime} 12^{\prime}$ N). Symptomatic tissues were surface-sterilized with $70 \%$ ethanol for $30 \mathrm{~s}, 2 \% \mathrm{NaClO}$ for $2 \mathrm{~min}$, dried and plated on potato dextrose agar (PDA). Colonies appeared after 3 days at $28^{\circ} \mathrm{C}$ in a light-dark cycle. They were cottony, initially white and turning dark brown. Mycelium was branched, conidiophores solitary. Conidia were solitary or in short chains pear-shaped or elliptical, brownish-yellow to dark brown with 1-3 transverse and 0-2 longitudinal septa, 23.0$45.1 \times 3.3-9.2 \mu \mathrm{m}$. ITS1/2 rDNA and RPB2 were amplified and sequenced with ITS1 and ITS4 (White et al. 1990) and fRPB2-7cR primers (Liu et al. 1999) respectively. The ITS1/2 and RPB2 sequences showed respectively $100 \%$ and $99.86 \%$ similarity to Alternaria tenuissima (Kunze) Wiltshire (MG211084.1 and LT707523.1). Pathogenicity was tested on guava seedlings in a glasshouse at $28{ }^{\circ} \mathrm{C}$ and $80 \%$ humidity. Wilt and necrosis appeared 10 days after woundinoculation on stems and leaves with 5-mm-diam mycelial discs of A. tenuissima. Control plants showed no symptoms. Alternaria tenuissima was re-isolated from the infected stems and leaves. This is the first report of brown spot disease in guava caused by A. tenuissima in China.

Funding information This work was supported by Guangdong Provincial Special Fund of Modern Agricultural Industry Technology Innovation Team (2019KJ108), Special funds for science and technology innovation strategy (R2018QD-059), and Guangdong Academy of Agricultural Sciences Dean's Fund (201708).

\section{References}

Liu YJ et al (1999) Phylogenetic relationships among ascomycetes: evidence from an RNA polymerse II subunit. Mol Biol Evol 16(12): 1799-1808

White TJ et al (1990) Amplification and direct sequencing of fungal ribosomal RNA genes for phylogenetics. In: Innis MA et al (eds) PCR protocols: a guide to methods and applications. Academic Press, San Diego, pp 315-322

Publisher's note Springer Nature remains neutral with regard to jurisdictional claims in published maps and institutional affiliations.
A. T. Peng

pengait@163.com

1 Guangdong Provincial Key Laboratory of High Technology for Plant Protection, Plant Protection Research Institute Guangdong Academy of Agricultural Sciences, Guangzhou, China 